Washington University in St. Louis Washington University Open Scholarship

Biology Faculty Publications \& Presentations

$3-2001$

\title{
Vertical and Horizontal Transcendence
}

\author{
Ursula Goodenough \\ Washington University in St Louis, goodenough@wustl.edu
}

Follow this and additional works at: https://openscholarship.wustl.edu/bio_facpubs

Part of the Biology Commons, and the Religion Commons

\section{Recommended Citation}

Goodenough, Ursula, "Vertical and Horizontal Transcendence" (2001). Biology Faculty Publications \& Presentations. 93.

https://openscholarship.wustl.edu/bio_facpubs/93

This Article is brought to you for free and open access by the Biology at Washington University Open Scholarship. It has been accepted for inclusion in Biology Faculty Publications \& Presentations by an authorized administrator of Washington University Open Scholarship. For more information, please contact digital@wumail.wustl.edu. 


\title{
VERTICAL AND HORIZONTAL TRANSCENDENCE
}

\author{
Ursula Goodenough
}

Draft of article published in Zygon 36: 21-31 (2001)

\begin{abstract}
Transcendence is explored from two perspectives: the traditional concept wherein the origination of the sacred is "out there," and the alternate concept wherein the sacred originates "here." Each is evaluated from the perspectives of aesthetics and hierarchy. Both forms of transcendence are viewed as essential to the full religious life.
\end{abstract}

KEY WORDS: transcendence, green spirituality, sacredness, aesthetics, hierarchy

\section{VERTICAL TRANSCENDENCE}

One of the core themes of the monotheistic traditions, and many Asian traditions as well, is the concept of transcendence. A description of this orientation from comparative religionist Michael Kalton (2000) can serve to anchor our discussion.

"Transcendence" both describes a metaphysical structure grounding the contingent in the Absolute, and a practical spiritual quest of rising above changing worldly affairs to ultimate union with the Eternal. For this thought-world it is self-evident that the finite, temporal, and contingent cannot stand alone without meaninglessness and absurdity, for then our basic questions (as posed by Plato) would have no answer, and our existence no direction or purpose.

Minds nurtured in this tradition find it an almost irresistible way of understanding how meaning becomes Meaning as the deeds of daily life are subsumed under some sort of (transcendent) paradigm or norm.

The infinite, eternal, personal creator by whose will we may live, and cosmic consciousness --the process and ultimate directional reality of one's own mind--are different metaphysical expressions of the familiar transcendence. They succeed equally in furnishing meaning by supplying a non-contingent purpose within all existence, described as the product of Divine will or as the inner nature of Being identified as consciousness. 
Traditional western forms of transcendence negate contingency not only by creating an absolute dimension, but also by writing humans into the very fabric of existence by framing mind or consciousness as the origin of the cosmos. Within this framework, one cannot but imagine that the emergence of our kind of consciousness represents the highest achievement in our world.

In this essay I first consider this phenomenon, which Kalton calls "vertical transcendence," from the perspective of aesthetics and hierarchy. I then turn to consider the dynamics of what Kalton terms "horizontal transcendence" from these same perspectives. I suggest that both forms of transcendence are seminal to our religious future.

\section{The Aesthetics of Vertical Transcendence}

Aesthetics is such a fussy, prissy word that it is absent from most vocabularies. It is defined in Webster as "the study or philosophy of beauty; theory of the fine arts and of people's responses to them," but the term has come to acquire negative connotations as well, as in the second definition of an aesthete as "a person who exaggerates the value of artistic sensitivity or makes a cult of art and beauty; believer in art for art's sake." The Greek root for an aesthete is aisthetes, a person who perceives, and to perceive, from the Latin percipere, is to take hold of, feel, comprehend. If we think of aesthetics as being about our particular human form of perception, then there is much that can be said.

Aesthetics is about order. Works of art are deeply structured, planned, thought through. Even when the work appears to be "improvised," like a jazz ensemble, the players are in fact listening to and for one anothers' structures and then developing their own in response. Many persons still harbor the concept that a painter or musician creates a work to let out some emotion - the art-astherapy notion - but this is a misunderstanding of what happens. As I have set out in an earlier essay (Goodenough, 2000), the artist begins with a concetto, a vision of what is to be conveyed, and then works with color and line and harmony to achieve a result that best actualizes the concetto. Even when the perceiver is not trained to analyze these structural components, their presence is deeply involved in the perceiver's aesthetic response to the work.

Aesthetics is also about coherence, which is close to order but has a separate manifestation. A work coherent to one perceiver may be incoherent to another, be it because of training - the elegance of a mathematical proof - or taste - abstract expressionism or 12-tone musical composition come to mind where taste is at least partially influenced by training. But the aesthetic power and aesthetic durability of an object can be correlated with its ability to elicit a 
sense of coherence in the perceiver. Some may fail to find a Jackson Pollack, say, coherent, but most will be able to distinguish a Pollack from a canvas of randomized drips as the more integrated, the more intelligible of the two. Even when we are quite unable to articulate what it is that we find intelligible about a work, we are nonetheless able to stammer that it all somehow comes together for us.

Aesthetics is of course also about beauty, that ineffable term that I will not attempt to define except to echo Keats that it has everything to do with deeply important kinds of truth. I will, however, offer Alfred Lord Whitehead's definition of beauty, as found in Haught (2000): "the synthesis of order with novelty, harmony with contrast, unity with diversity." Clearly, order and coherence infuse most attempts to articulate what beauty is about.

And finally, aesthetics is about something that has a purpose. Even if its purpose is only about being about beauty. Ellen Dissanayake has written a book called "What Is Art For?" (1988), and her answer, after reviewing the many answers on offer, is that art serves to make something special. Regardless of the answer we choose, the point is that What is Art For? is a question to be asked. This poem is about sorrow, this painting explores the use of pastels to create light, this composition augments a Hungarian folk melody, this totem tells stories of the gods of the tribe.

Vertical transcendence, in the sense of subsuming dailiness under some sort of paradigm or norm, some absolute dimension, has everything to do with order, coherence, beauty, and purpose. There is a seamlessness about a transcendent worldview that is of the same quality as a Beethoven string quartet. Taste is again operant here in the sense that a particular transcendent vision may be experienced as Meaningful to one person and not to another, where for many these choices are deeply informed by early encounters with transcendent concepts. But the larger point is that to the extent that we are responsive to aesthetic experience, so too are we also responsive to opportunities for vertical transcendence.

But here we arrive at a second perspective. By writing humans into the very fabric of existence, by framing mind or consciousness as the origin of the cosmos, we take our human form of perception - our aesthetics - and transpose them onto the cosmos. The cosmos, experienced transcendently, is about order, coherence, beauty, and purpose because these are our aesthetic foundations. Gods are revealed to us who design, who have a plan, who radiate beauty and truth. And we are satisfied.

\section{Hierarchy and Vertical Transcendence}

Vertical transcendence is a hierarchical vision. Theologian John Haught suggests that the original etymology of "hierarchy" is that all things have their 
origin (arche) in the domain of the sacred (hier). In the passages below, Haught echoes Kalton's description of vertical transcendence but stresses the importance of its hierarchical component (Haught, 2000):

According to many religious traditions, in order to have a meaning or purpose the universe had to be structured hierarchically. It had to consist of at least several levels, typically thought of - moving from lower to higher - as the inanimate, the living, the sentient, and the self-aware. Presiding over all of these levels was a hidden but eminently real Source of meaning, identified in theistic faiths as "God."

The persistent attraction of such a hierarchical scheme is that it embeds the temporal world within the framework of an eternal, absolute and sacred reality immune to transiency and death. Only participation in such a Permanence can give final meaning to the perishable flux of finite existence..... In the absence of such a framework it is difficult to imagine how the universe could have any abiding purpose. Outside of a hierarchical setting there would be only a flattened-out cosmos with no "other dimension" to redeem it or give lasting importance to it. We could have no sense that the temporal participates in the eternal, or that there is any transcendent value, importance or meaning to the evanescent physical universe and our own fleeting lives.

Haught tries to distance this "ancient" concept of hierarchy from its modern "patriarchal" usage, but to my ear the two are homologous. "Hierarchy" denotes any system that employs a classification by rank, and hierarchies abound in every nook and cranny of every human culture, from schoolyards to corporations to politics to athletics to street gangs. Nor is our orientation in hierarchy some cultural artifact. It is as rooted in human nature as is our aesthetic sensibility. Most social mammals, and certainly most primates, organize themselves in hierarchical strata. Alpha males, alpha females, sexual preference, rank by birth order or seniority or physical strength or mental acuity to be aware of these distinctions, to align ourselves within them and attempt to achieve higher status, is as natural to us as our affinity for order, coherence, beauty, and purpose. And indeed, these natures are deeply enmeshed. To trans-cend is to climb over, go beyond, surpass. The direction is vertical; the ultimate and the absolute are at the top. Order triumphs over messiness, coherence negates confusion, beauty trumps ugliness, purpose defeats meaninglessness. As we ascend in our aesthetic experiences, so do we satisfy our hierarchical impulse to rise above what we were.

Nowhere is the confluence of transcendence, aesthetics, and hierarchy more integral than in religious art. A totem is hierarchy all the way up. The mosque towers over the city, the church spire soars, the choir builds with ascending crescendos, the robes and miters of the clergy augment the human 
form. Hierarchy also steeps religious ritual: the pastor looks down from the pulpit; the jeweled ark holds the uplifted Torah; to partake of the Eucharist or the blessing or the sacrifice is to become larger and more godlike. We fall when we sin, we rise when we are saved.

Our hierarchical nature of course operates as well in that which brings us our deepest shame: war, genocide, enslavement, greed, arrogance, and a tolerance for the poverty and suffering of others. Many of our laws and creeds are efforts to deconstruct such manifestations of hierarchy, or at least bring them under some kind of control. But they pop up again, willy-nilly, because hierarchy is part of our nature. Our affinity with the Ultimate and the Absolute flows up from the same psychological bedrock that generates much of our sin.

\section{Horizontal Transcendence}

"Horizontal transcendence" is inherently an oxymoron in that it ignores the climbing-over etymology of "transcendence." Haught would doubtless also say that it represents a contradiction in terms since, from his perspective, the horizontal is toxic to transcendence.

Outside of a hierarchical setting there would be only a flattened-out cosmos with no "other dimension" to redeem it or give lasting importance to it....A hierarchical view of reality is, I believe, essential...to any satisfactory conception of cosmic meaning.

The (scientific) discovery of time's immensity itself allows us to "horizontalize" and finally altogether dissolve the old hierarchical picture.... By flattening what used to be thought of as an essentially vertical arrangement of being and value, science seems to have destroyed the cultural, ethical and religious setting in which human life has carried on for ages....We cannot exaggerate the enormity of the great drama of hierarchical collapse that has accompanied the rise of science.

Haught's response to this collapse is to suggest ways that hierarchies can be reinstated in the context of our scientific understandings, citing Polanyi's concept of levels of emergence, Teilhard de Chardin's notion that "our unfinished universe orients itself - at this point in its evolution - towards its ultimate destiny," and Whitehead's suggestion that "the universe is structured so as to strive openendedly and experimentally towards more and more intense versions of beauty."

In contrast to Haught, Kalton regards horizontality to be a germinative, if challenging, dimension of transcendence. Here are some of his perspectives. 
Humans remain at the center of any world view premised on mind or consciousness. A radically non-anthropocentric spirituality does not incline towards such a premise.... (Darwin) posed a vision of the evolution of life in which mind or consciousness were neither origin nor purposeful end achievements. Mind within the framework of natural selection has no inherent claim to superiority, nor can it escape the pragmatic question, "what is it good for?"

Horizontal transcendence... finds its anchor in life rather than mind, thus displacing human consciousness from its privileged place. The movement from earth to cosmos, from biosystem to life, is a form of transcendence that is characteristic of degrees of abstraction rather than a movement towards some kind of Absolute metaphysical dimension. There is no cosmos posited apart from the historically ongoing one within which we find ourselves, nor is there life apart from ongoing living, at whatever level it is considered. Instead of the typical vertical transcendence of the Greek inspired tradition, the movement of this kind of spiritual cultivation is horizontal, perfecting our relationship with the world of life about us.

The biocentered life orientation ... locates its center of value, meaning, and purpose squarely within the realm of the contingent,... the very kind of irredeemable contingency identified with meaninglessness and absurdity within conventional transcendent frameworks. Indeed, contingency itself is a central element of its salvific message.... Until we grasp our radical contingency, we have small chance of really understanding the nature of what is at stake.

Horizontal transcendence to the vast scope of temporal process prior and consequent to human or even earth existence is a different challenge, for it does not relate to our goals and projects with either an ultimate affirmation or negation. Rather it connects with the effort itself, as our mode of manifesting and experiencing a dynamic that is coextensive with the process of life.

I consider next the dynamics of such a horizontal transcendence from an aesthetic and then a hierarchical point of view.

\section{The Aesthetics of Horizontal Transcendence}

Our quest for vertical aesthetic experience is rewarded by Nature in countless contexts -- the soaring Alps, the magnificent sunset, the spectacular waterfall - where we encounter pattern, order, and outrageous beauty. We also arrange Nature such that she conforms to our vertical aesthetic sensibilities, creating flower gardens and bird sanctuaries and scenic ocean views. But if this 
were the aesthetic argument for Nature, then most of Nature would fail to make the vertical cut. Most of Nature is messy -- the rainforest is thick and impenetrable, the swamp is infested, the field is a tangle, the river floods and rages. We need to look elsewhere in our human nature to locate a horizontal aesthetics that resonates with Nature as she ordinarily manifests herself, since otherwise we are consigned, in the future, to experience her only in scenic preserves where she is rendered orderly, coherent, beautiful, and, hence, somehow purposeful, like our minds.

That we possess as part of our genetic heritage an aesthetic for the natural is readily affirmed by taking a young child for a walk in the woods or by the sea and witnessing her innate delight in all she beholds. The delight has little to do with sunsets or vistas, with order or pattern or purpose. The delight is with the particular: the ladybug crawling on the rock, the fuzzy moss, the tickly dunegrass, the mucky mud by the river. Children connect with the immediate and become a part of it. The mud isn't messy, or rather, its messiness is what makes it wonderful. Children are inherently attuned to Nature.

The attunement of the child is the aesthetic of the mammal. For the mammal (and all creatures), experience is not expected to be orderly or coherent. It is expected to be about participation in, and relationship with, an environment that is ongoing, changing, and unpredictable. Whether a child's pleasure in this participation feels the same as it does to other mammals is not easily proven, but when I watch dogs and children running across a field, laughing and barking, it looks pretty much the same to me.

We can therefore say that the aesthetics of horizontal transcendence is about responding to the nature of nature with attunement and participation and delight. The child does this spontaneously. Why is it so hard for so many of the rest of us?

\section{Hierarchy as Homecoming}

The big problem seems to arise when we leave the romp of childhood and encounter the hierarchically framed imperative to seek Meaning, at which point the ongoing, changing, unpredictable nature of nature - its contingency - and our non-central status within it -- our contingency -- become disturbing and disorienting. We also learn from our science that contingency operates all the way down, from quantum indeterminacy to natural selection to the dynamics of speciation. As noted earlier, constructive theologians like Haught seek ways to discern a larger order, and hence Meaning, in Nature's atomistic, historicized gestalt, the goal being to re-infuse Nature with a hierarchical dimension. Kalton, by contrast, challenges us to consider contingency as central to the salvific message of a biocentered orientation. How might this be configured? 
As we have said, Haught's definition of "hierarchy" is that all things have their origin (arche) in the domain of the sacred (hier). He locates the domain of the sacred as that which stands above the contingent: Origination is top-down. What Kalton is suggesting is that we re-locate the domain of the sacred, finding it instead in the messy contingency of Nature, and in so doing, think of origination as a bottom-up process.

Having written a book called "The Sacred Depths of Nature," (Goodenough, 2000), the etymology and the meaning of the word sacred often come up in discussions. To be sure, its standard usage resides in vertical hierarchical contexts, the notion being that things become sacred, and hence shed their contingency, only when consecrated by a higher Purpose, a Sacralizer. But if we are considering the use of transcendence to mean a horizontal orientation, thereby rotating the concept by 90 degrees, then sacredness must also be reconfigured. If we are to sacralize Nature, as she comes to us, then this entails rotating the concept of hierarchy by 90 degrees and locating our arche in the hier of the natural world. We can then, as Kalton puts it, "celebrate our status as members of the biosystem as a sort of homecoming."

In this kind of horizontally framed spirituality the question of belonging acquires a new kind of centrality. Recovering a more sacral sense of the earth and universe starts us on the way. But coming from a background of traditions premised on a discontinuity between ourselves and the rest of the natural world, inevitably many of our ordinary ways of thinking and acting carry the imprint of that discontinuity. Belonging is an achievement as well as a statement of fact, and the path to such achievement leads through a reexamination of basic habits of mind.

One of these habits of mind is the hierarchy of levels, of moving from lower to higher, from the inanimate to the living to the sentient to the self-aware. Kalton opens this up for us as well:

A reexamination of how we regard the "non-living" aims to open the possibility of a mode of self-identification which transcends the boundary of biotic life. Once the boundary is down, an arena of immediate access to horizontal transcendence is created. What the poet Robinson Jeffers has referred to as "the massive mysticism of stone" surrounds us, inviting us to discover the patterning that lives in geologic time or even cosmic time, substrate to patterns manifest in the rapid complexity of life time. What is it from which we have emerged, and to which we return at death? It cannot be less than us, for we are formed of it, belong to it, manifest it. 
All religious orientations offer Reward, with the Reward of hierarchical theistic traditions being unification with a Purposeful Creator. For Kalton, and in general for the religious naturalist, the reward of a horizontal orientation is the homecoming.

The horizontal transcendence of belonging to the universe (is) premised on life rather than mind. Such transcendence does not deny our contingency, but it provides a deeply grounded belonging that extends beyond human life or even the earth itself.

The life system that evolved into us can be permitted a full historical contingency, and yet be moored in a wider life process, a mysterious, religiously enshrined becoming.

In discovering a dimension of life running as a fundamental thread in the forces and processes of the universe, we find grounds for an affirmation that reaches beyond the life of our kind. This horizontally transcendent affirmation does not delude us with a questionable sense of permanence, but no less than other forms of transcendence, it sustains us with a sense of awe and reverence for the mystery that encompasses us.

\section{COMBINING THE TWO}

Horizontality

A key component of any religious orientation is the ethical framework that it elicits. Nowhere does the contrast between vertical and horizontal alignment become more palpable than in the context of ethics. Here is Haught:

To deny the reality of a sacred "arche" or "Principle" would make it very difficult for us to attribute enduring importance or meaning to anything.

If we lose our trust that the cosmos is at heart an expression of a transcending significance, our ethical aspiration will quite likely wither and die.

And here is Kalton:

We are now, and always will be, situated beings; we exist always and only enmeshed in the relational reality of surroundings and situation. There is no alternative to being here now, so the question of fitting is really not a matter 
of how we fit in some ideal scheme but a question of the appropriateness of our response to the situation in which we find ourselves.

The feasibility of the experiment remains an open question. This can be salvific knowledge: if we can see that we are embarked on a mighty experiment, then we might scrutinize with a more observant and questioning mind just how the experiment seems to be working and what we might do about it.

We are responsive to and responsible to not geologic time but to our own moment, with success and failure measured in terms of passing on a flourishing life to our kind and to the web of all kinds with which we are interwoven. To experience this as an urgent and engrossing problem is inherent to the fundamental dynamics of life itself.

For me, Kalton's horizontal vision is engrossing and germinative, whereas locating the sacred in some other realm leaves me ethically bankrupt. My ethical aspirations are animated by my apprehension of the immediate, by my sense of belonging and relatedness. In the horizontal mode, spiritual cultivation is a shared experience; in the vertical mode it is solitary and unrooted.

Moreover, I am frankly apprehensive about continuing to turn ethics over to hierarchical modes of understanding. The apprehension of what is Right too often generates a meta-ethics that is anthropocentric or materialistic or xenophobic, and the institutions that come to administer these understandings themselves succumb to vertical frames of mind. I believe we need to organize our moral obligations around our horizontal sensibilities.

From my perspective, the core underpinnings of the moral life are empathy, fair-mindedness, courage, and reverence/humility, impulses that flow forth from our evolutionary heritage. As we have noted earlier, that same heritage also harbors hierarchical impulses of the darker kind, impulses that would oppress and pave over in the name of fear and greed. To move forward, our religious life must include joyous reminders that our ethical impulse to do right by others is embedded in our being, and that the dark impulses that are also embedded in our being must somehow be overcome by the light. This has, of course, always been our ethical challenge, but we are now able to frame it, and address it, in an evolutionary context.

Horizontal ethics are undergirded by horizontal aesthetics, by our childhood attunement with Nature, our delight in participating in the great unfolding. One of the tragedies of our cultural heritage is that this attunement becomes so buried in human artifact that far too many of us come to regard Nature as a thing, to be controlled and exploited. Alas, the vision that 6 billion humans might have regular opportunities to wander about in the woods is just 
that -- a vision, for many a laughable vision. But religions are about visions, and to embrace green spirituality is to hold in one's heart the vision that our inborn attunement will be fostered and celebrated.

Also central to a horizontal ethics is that our children be told of our scientific understandings of Nature at their mothers' knee, with wonder and gratitude and respect. A child who learns that the beautiful tree is genetically scripted, that his thoughts and feelings are generated by neurochemistry, and that the magnificent sun is a raging fireball of thermonuclear reactions - that child learns to experience Nature the way she is, becoming fluent in her language and grounded in the bracing contingency of it all. An ethical approach to Nature must be anchored both in deep attunement and deep knowledge.

\section{Verticality}

It is not enough to blame acculturation for our loss of horizontal aesthetics. As we mature and our hierarchical impulses surge into awareness, most of us find it easier to respond to the vertical than to the horizontal. To access the massive mysticism of stone is a far greater challenge than to access the mysticism of that stone after it has been converted into the soaring vault of a cathedral.

Happily, we can have both.

We can learn, or rather, re-access our childhood wonder and exaltation in the messy contingency of the horizontal, seeking not to order it but to experience it. Horizontal transcendence is not about hierarchy. It is about being part of the whole, being alive at all. It is infused with humility.

Vertical transcendence is all about hierarchy, but interestingly, it also generates humility, albeit by a different path. As we are up-lifted, be it by a magnificent mountain or a choral performance or an encounter with the Divine, so too are we humbled, overwhelmed with gratitude.

So, if we are to envision a planet infused with horizontal transcendence, that dream is best realized, I believe, if we insist that our planet be immersed as well in vertical aesthetics, wondrously engaging our hierarchical frames of mind. Access to the arts should be a birthright, just like the walks in the woods, with our cities rendered beautiful and our artists revered. We can and should be thrilled by our kind of vertical aesthetic consciousness, our passion for order and coherence and beauty and purpose, not because it represents the highest achievement in our world but because we are blessed to have it. Whether we go on to attribute these "higher" orientations to the plan of God or the luck of the evolutionary draw is an individual choice, about which there need be no acrimony once we realize that such matters of belief spring forth from common states of grace. 
Coda: Juanita

Juanita grew up in the South Bronx with her Hispanic mother, a woman who was intensely fearful of all things natural and conveyed these fears successfully to her daughter. But now Juanita was married to a man who had grown up in the Puerto Rican countryside and loved the sea, and she was determined not to transmit her anxieties to her nine-month-old daughter. When they came to visit us on Martha's Vineyard, she was apprehensive about the ferry and nervous about our house in the woods, but it was when we driving down the dirt road to the beach that I became aware of the depth of her terror: her whole body was trembling as we moved along the wild open wetlands. "There's nothing here," she stammered. "It's empty. I'm so so scared."

She was wearing a large ornate crucifix, so I asked if she was Christian and she said yes, Roman Catholic, in a way that let me know that she had had many experiences of important vertical transcendence. So I began talking about God, about how this was God's work, how the Bronx and the church were the work of humans but that this was how God offered the world to us, untamed and open and tangled with creatures other than ourselves.

And there came to happen what can only be described as an epiphany. "This is God's beauty," she repeated again and again as we walked, arm in arm, the baby on her hip, over the dune and onto the beach. The vastness of the ocean and the pounding surf again generated almost uncontrollable trembling, but she repeated her mantra and slowly calmed and opened, at first insisting that she sit as close as possible to the protecting dune but then slowly, slowly, inching her blanket forward until, in an act of affirmation that moved me to tears, she walked to the water's edge, put her bare feet in the ocean, and then leaned over and put her baby's feet in the ocean. A horizontal baptism in the crucible of vertical faith.

\section{REFERENCES}

Dissanayake, E. 1988. What is Art For? Seattle: University of Washington Press.

Goodenough, U. 2000."Reflections on Scientific and Religious Metaphor." Zygon 35: 233-240.

Goodenough, U. 1998. The Sacred Depths of Nature. New York: Oxford University

Press. 
Haught, J.F. 2000. "Science and the Quest for Cosmic Purpose." Future Visions (www.meta-list.org/futurevisions/).

Kalton, M. 2000. "Green Spirituality: Horizontal Transcendence." In Paths of Integrity,

Wisdom and Transcendence: Spiritual Development in the Mature Self, ed. M.E.

Miller and P. Young-Eisendrath. ${ }^{* * *}$ : Routledge. 

